\title{
Numerical investigation on effect of leaflet thickness on structural stresses developed in a bileaflet mechanical heart valve for its sustainable manufacturing
}

\author{
Syed Samar Abbas ${ }^{1}$, Mohammad Shakir Nasif ${ }^{1,}$, , Mior Azman Meor Said ${ }^{1}$, Rafat \\ Al-Waked ${ }^{2}$, and Saleem Khalefa Kadhim ${ }^{3}$ \\ ${ }^{1}$ Mechanical Engineering Department, Universiti Teknologi PETRONAS, 32610, Seri Iskandar, \\ Malaysia. \\ ${ }^{2}$ Mechanical and Maintenance Engineering Department, School of Applied Technical Sciences, \\ German Jordanian University, Amman 11180, Jordan. \\ ${ }^{3}$ Control and System Engineering Department, University of Technology, Baghdad, Iraq
}

\begin{abstract}
Flow induced structural stresses can cause mechanical prosthetic aortic valve to fail due to yielding. In this study, we have performed the structural analysis, especially the effect of leaflet thickness on equivalent stresses developed in a Bileaflet mechanical heart valve (BMHV) due to blood flow through it has been investigated. The leaflet thickness varies from $0.5 \mathrm{~mm}$ to $0.7 \mathrm{~mm}$, by $0.1 \mathrm{~mm}$. A fluid-structure interaction approach based on Arbitrary Lagrangian Eulerian (ALE) technique has been employed with the aid of an user defined function (UDF). Results of the analysis show that high von Mises stresses are developed in BMHV with leaflet thickness of $0.5 \mathrm{~mm}$ and $0.6 \mathrm{~mm}$, being $75 \%$ and $13 \%$ higher than allowable equivalent stress respectively. Such thinner leaflets are therefore, not sustainable to be replaced with diseased aortic valve.
\end{abstract}

\section{Introduction}

The native aortic valve may be diseased due to inborn heart defects, rheumatic fever, bacterial infection etc. and thus can cause stenosis or valvular insufficiency [1]. A prosthetic replacement to such malfunctioning valve can be made with a 'Bileaflet Mechanical Heart Valve' (BMHV), which consists of two leaflets, housing and suture ring as shown in Fig. 1 [2].

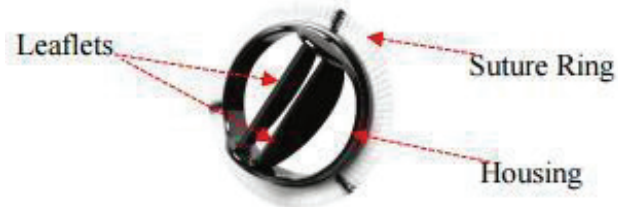

Fig. 1. A typical BMHV

* Corresponding author : mohammad.nasif@utp.edu.my 
To have a deep insight into the fluid dynamics of prosthetic valves, numerical methods have evolved as a great tool in the past half century, originating with the pioneering work of Peskin et al. [3]. In his work, a two-dimensional numerical model of mitral valve was presented. The numerical simulation of prosthetic valves is a complex Fluid-structure Interaction (FSI) problem, which has to deal with kinematical description of the fluid domain. Based on this, the numerical models either employ a fixed or a moving grid approach. Due to their high accuracy, moving grid approaches are preferred over fixed grid methods [4,5]. Moving grid approaches are based on Arbitrary Lagrangian Eulerian (ALE) method, in which the fluid grid moves in an arbitrary way and it doesn't have to conform with fluid velocity. With ALE, greater distortions of the continuum can be handled better than would be allowed by a purely Lagrangian method, with more resolution than that afforded by a purely Eulerian approach [6]. Having applied ALE to 2-D geometry of BMHV, Dumont et al. [7] obtained velocity profiles for systolic phase of cardiac cycle and validated the results experimentally. Nobili et al. [8] and Yeh et al. [9] developed a 3-D model of the valve, and employed ALE to study hemolytic properties of blood flow during different phases of cardiac cycle. Their results were found in good agreement with experimental measures. It's important to note that due to large structural displacements involved while simulating BMHV, subsequent remeshing and smoothing is required to maintain a good quality mesh [10].

The structural strength of BMHVs is an important matter while designing the valve as structural stresses are developed in the valve due to blood flow that may cause valve failure. During its lifetime operation, the valve is exposed to blood pressure force [11], force due to regurgitant flow at the end of systole [12] and due to vortices formed in the wake region downstream the BMHV [13]. High equivalent stresses may cause yielding and thus failure of the structure. Kwon et al. [14] performed structural analysis of such valves with variable leaflet thicknesses by considering the effect of blood pressure force only. It was reported in his study that considerably thin valve (with thickness $0.5 \mathrm{~mm}$ ) undergo failure due to yielding. Some other studies have also considered the effect of leaflet thickness variation over the structural strength of valve experimentally $[15,16]$ and have reported that the structural strength decreases with decreasing thickness. In another numerical study by Kwon et al. [17], a blood pressure force of $104 \mathrm{KPa}$ was applied, even though the physiological blood pressure exerts a force of $16 \mathrm{KPa}$ only [14]. The excess force was applied to account for lifelong and continuous exposure of leaflets to the blood pressure force.

Considering the effect of varying leaflet thickness and consequently, that of hinges, we have performed structural analysis of a BMHV, subjected to not only the blood pressure force, but also to the force due to recirculation of blood and regurgitant flow. The thickness of the leaflet has been varied between $0.5 \mathrm{~mm}$ to $0.7 \mathrm{~mm}$ [14], and hence the thickness of the hinges, by an interval of $0.1 \mathrm{~mm}$. A fluid-structure interaction model based on ALE has been employed. The von Mises stresses induced in the structure are computed and compared for various thickness. To the best of our knowledge, no previous study has performed such analysis while considering Fluid-structure interaction of blood flow through a BMHV.

\section{Methodology}

The geometric model of the aortic root containing BMHV has been developed using the experimental design presented by Reul et al [18], as shown in Fig 2. Aortic root is the initial tract of aorta, and is characterized by three bulbous sinuses of Valsalva [19]. BMHV is located at the initial verge of aortic root and consists of two leaflets made up of pyrolytic carbon, which fully closes at $25^{\circ}$ while fully opens at $85^{\circ}$. The leaflets rotate about struts attached to their housing, which is made up of titanium. Leaflet with a thickness of $0.5 \mathrm{~mm}$ 
can be seen in Fig 3. The thickness is varied from $0.5 \mathrm{~mm}$ to $0.7 \mathrm{~mm}$ and complete cardiac cycle has been simulated for all the aforementioned thicknesses of the leaflet. Simulations have been carried out using finite volume code ANSYS Fluent coupled with finite element code Static Structure. The number of cells used in Static Structure and Fluent are 151,426 and 723,771 , respectively and maximum mesh skewness of 0.76 was maintained.

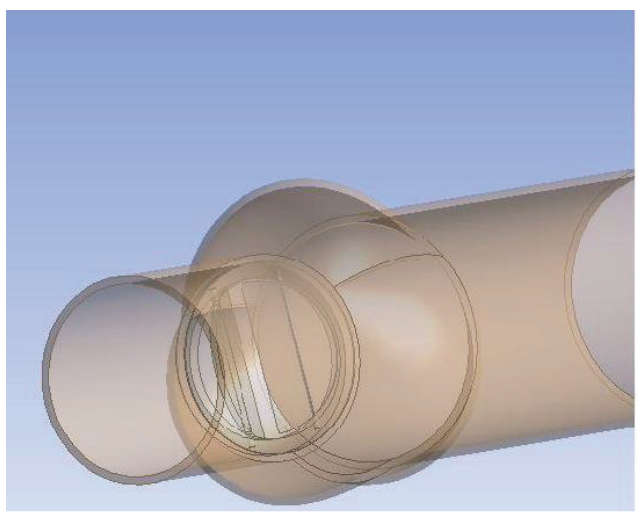

Fig. 2. Aortic root geometry

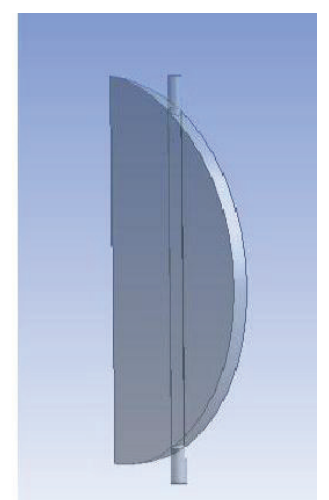

Fig. 3. Leaflet with thickness $0.5 \mathrm{~mm}$

ANSYS Fluent has been used as fluid solver with an in-house written user defined function to account for the movement of the two leaflets. The code was written using $\mathrm{C}++$ programming language and was then incorporated into ANSYS Fluent. Dynamic mesh module of ANSYS Fluent has been used in conjunction with remeshing.

The set of Navier Stokes equations that the software solves for the fluid domain are as written in equations (1) and (2):

$$
\begin{gathered}
\nabla \cdot v=0 \\
p\left(\frac{\partial v}{\partial t}+v \cdot \nabla v\right)=\nabla \cdot \sigma+p \cdot f
\end{gathered}
$$

Where, $p$ is the fluid density, $v$ is the fluid velocity, $\sigma$ is the Cauchy Stress tensor and $f$ the body force.

A no-slip boundary condition has been applied to wall boundary. Blood has been modelledas laminar, Newtonian fluid, since the Newtonian behaviour of blood in large vessels like aorta has been widely agreed [18]. The viscosity of blood becomes asymptotically constant at high shear rates, which is the case for aorta. The blood's dynamic viscosity and blood density used in the model are $3.5 \mathrm{cP}$, and $1060 \mathrm{~kg} / \mathrm{m} 3$ respectively.

A physiological pressure waveform, which was approximated using the Fourier series, has been incorporated as the inlet and outlet boundary condition, as mentioned in equations (3) and (4) respectively [8]. The governing equations for inlet and outlet pressures are listed below: 
$p($ inlet $)=44.24-50.76 \cos w t+44.4 \sin w t-0.4108 \cos 2 w t-$

$19.45 \sin 2 w t-0.3481 \cos 3 w t+6.66 \sin 3 w t+8.032 \cos 4 w t+2.597 \sin 4 w t+$

$0.3551 \cos 5 w t+2.903 \sin 5 w t$

where w represents a factor in the pulsed wave equation and is equalled to 8.72 .

$$
\begin{aligned}
& p(\text { outlet })=96.71-18.66 \cos w t+2.59 \sin w t+0.182 \cos 2 w t- \\
& 8.67 \sin 2 w t+4.41 \cos 3 w t+0.46 \sin 3 w t+0.059 \cos 4 w t+ \\
& 1.39 \sin 4 w t-2.101 \cos 5 w t+1.19 \sin 5 w t
\end{aligned}
$$

where $\mathrm{w}$ is equal to 8.438 .

\section{Results and Discussion}

The von Mises stresses developed in the valve structures of leaflet's thickness $0.5 \mathrm{~mm}, 0.6 \mathrm{~mm}$ and $0.7 \mathrm{~mm}$ are presented in Fig. 4 and Fig. 5 respectively at fully closed position of the leaflets $\left(25^{\circ}\right.$, time $\left.0.8 \mathrm{sec}\right)$, while the stresses for other significant positions of the leaflet as start to open $\left(30^{\circ}\right.$, time $\left.0.008 \mathrm{sec}\right)$, fully open $\left(85^{\circ}\right.$, time $\left.0.057 \mathrm{sec}\right)$ and start to close position $\left(63^{\circ}\right.$, time $\left.0.237 \mathrm{sec}\right)$ are listed in Table 1 . It has been highlighted in previous studies that the valve structure is subjected to maximum stress at fully closed position and our results conform with this statement. Higher von Mises stresses than allowable range are developed in leaflets with thickness of $0.5 \mathrm{~mm}$ and $0.6 \mathrm{~mm}$ both at fully closed positions of the leaflets. This is contrary to results of Kwon et al [14,17] in regard that in their study, it was reported that von Mises stresses higher than the allowable range are developed in leaflets of thickness $0.5 \mathrm{~mm}$ only. This is majorly due to the reason that they ignored recirculation and regurgitant flow in their study, subjecting the valve to blood pressure force only and therefore, the equivalent stresses in leaflets with thickness of $0.6 \mathrm{~mm}$ were under-estimated.

It is the hinge region that develops the maximum von Mises stresses for all thicknesses. The maximum von Mises stress developed in leaflets with thickness $0.5 \mathrm{~mm}$ is $56 \mathrm{MPa}$, being 1.5 times higher than those developed in leaflet thickness of $0.6 \mathrm{~mm}$ (being $36 \mathrm{MPa}$ ) while 5.5 times higher than those developed in leaflet thickness of $0.7 \mathrm{~mm}$ (being $11 \mathrm{MPa}$ ). These stresses occurred at the leaflet pin for a short time, however it may cause valve failure in the long run due to yielding as the allowable stress is $32 \mathrm{MPa}$ [22].

The von Mises stresses developed in leaflet thickness of $0.5 \mathrm{~mm}$ at start to open $\left(30^{\circ}\right.$, time $0.008 \mathrm{sec})$ and start to close position $\left(63^{\circ}\right.$, time $\left.0.237 \mathrm{sec}\right)$ are also higher than the allowable range, being $45 \mathrm{MPa}$ and $35 \mathrm{MPa}$ respectively (Fig. 4). Other than mentioned above, for all leaflet's thicknesses and positions, the stresses are within the allowable range. It is worth mentioning that for leaflet thickness of $0.7 \mathrm{~mm}$, the von Mises stresses developed during the whole cardiac cycle are well below the allowable range, with maximum equivalent stress being $11 \mathrm{MPa}$ only.

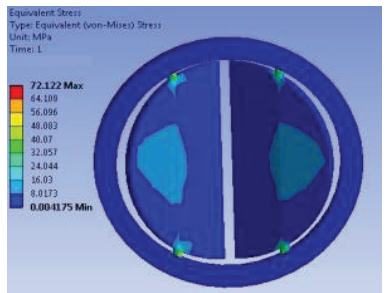

(a) Fully closed

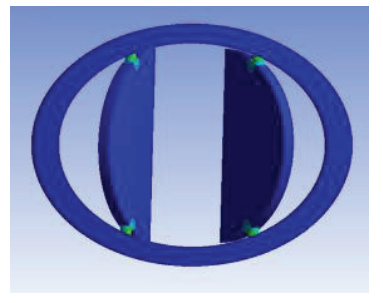

(b) Start to close

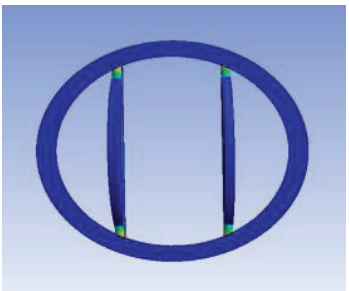

(c) Fully open

Fig. 4. von Mises stress profiles for different positions of leaflets with thickness $0.5 \mathrm{~mm}$. 

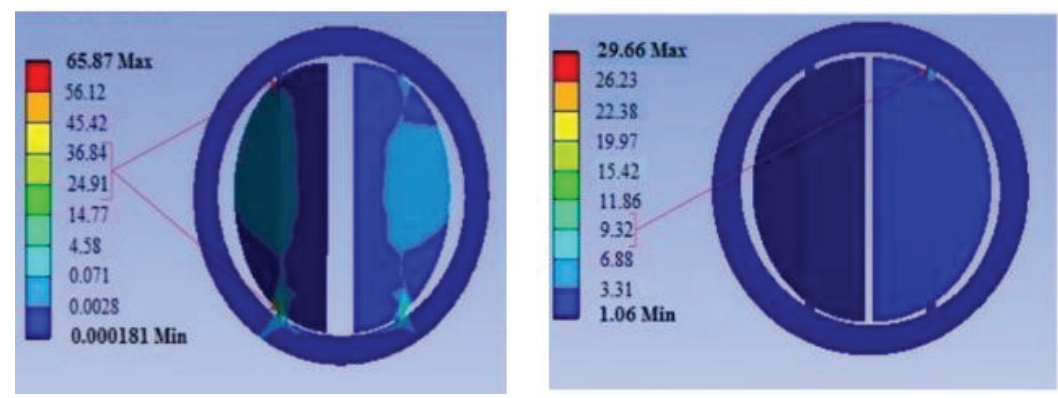

Fig. 5. von Mises stress profile for $0.6 \mathrm{~mm}$ and $0.7 \mathrm{~mm}$ thick leaflets

Table 1. von Mises stresses for variable leaflet thickness at different physiological positions of the valve leaflet

\begin{tabular}{cccc}
\hline & $\mathbf{0 . 5} \mathbf{~ m m}$ & $\mathbf{0 . 6} \mathbf{~ m m}$ & $\mathbf{0 . 7} \mathbf{~ m m}$ \\
\hline Leaflet's Position $\left.\boldsymbol{( \theta}^{\mathbf{0}}\right)$ & $\begin{array}{c}\text { von-Mises stress } \\
(\mathbf{M P a})\end{array}$ & $\begin{array}{c}\text { von-Mises stress } \\
(\mathbf{M P a})\end{array}$ & $\begin{array}{c}\text { von-Mises stress } \\
(\mathbf{M P a})\end{array}$ \\
\hline 25 & 56 & 36 & 11 \\
30 & 45 & 30.5 & 9 \\
63 & 35 & 24 & 5.5 \\
85 & 14 & 11.5 & 3.5 \\
\hline
\end{tabular}

\section{Conclusion}

von Mises stresses developed in a Bileaflet mechanical heart valve with variable leaflet's thicknesses have been presented in this paper, when it is subjected to physiological blood flow. The thickness of the leaflet varies from $0.5 \mathrm{~mm}$ to $0.7 \mathrm{~mm}$, by an interval of $0.1 \mathrm{~mm}$. It has been observed that high von Mises stresses than the allowable range are developed in thinner leaflets of thickness $0.5 \mathrm{~mm}$ and $0.6 \mathrm{~mm}$. The hinge region of the leaflets has been observed to be subjected to high equivalent stresses. Such leaflets can fail due to yielding and therefore, are not suitable for sustainable design of BMHV. A $0.7 \mathrm{~mm}$ thick leaflet has been found to develop very low equivalent stresses than the allowable range, and is therefore recommended for sustainable manufacturing of BMHV.

\section{References}

1. T.H. Hong, C.R. Choi, C.N. Kim, Eng. Technol. 25 pp. 679-684 (World Academy of Science, Engineering and Technology, France, 2009)

2. F. Zhou, Y.Y. Cui, L.L. Wu and J. Yang, L. Liu, M.F. Maitz, I.G. Brown and N. Huang, Jr. of Med. and Bio. Engg., 36 pp. 110-120 (Biomedical Engineering Society of the R.O.C., Taiwan, 2016)

3. C.S. Peskin, Jr. of Comp. Phys., 25 pp. 220-252 (Elsevier, United States, 1977)

4. E. Kuhl, H. Askes, P. Steinmann Comput. Methods Appl. Mech. Engrg. 193 pp. 42074222(Elsevier, United States, 2004)

5. C. Michler, S.J. Hulshoff, E.H. Brummelen, R. Borst, Computers \& Fluids, 33(5) pp. 839-848 (Elsevier, United Kingdom, 2004)

6. J. Donea, S. Giuliani, J.P. Halleux, Comput. Methods Appl. Mech. Engrg., pp. 689-723 (Elsevier, United States, 1982) 
7. K. Dumont, J.M. Stijnen, J. Vierendeels, F.N. van de Vosse, P.R. Verdonck, Comput Methods Biomech Biomed Engin. 3 pp. 139-146 (Taylor and Francis, United Kingdom, 2004)

8. M. Nobili, U. Morbiducci, R. Ponzinic, C.D. Gaudiod, A. Balduccid, M. Grigioni, F.M. Montevecchib and A. Redaelli, Journal of Biomechanics, 41 pp. 2539-2550 (Elsevier BV, Netherland, 2008)

9. H.H. Yeh, D. Grecov and S. Karri, Journal of Medical and Biological Engineering, 34(5) pp. 482-486 (Biomedical Engineering Society of the R.O.C., Taiwan, 2014)

10. V.T. Nguyen, Y.T. Kuan, P.Y. Chen, L Ge, F Sotiropoulos, A.P. Yoganathan and H.H. Leo, Cardiovascular Engineering and Technology, 3 pp. 88-100 (Springer, United States, 2012)

11. Y. J. Kwon, C. N. Kim, J. W Lee, KSME International Journal, 17 pp. 1316-1323. (2003)

12. J. Mazumdar, An introduction to Mathematical physiology and biology (Cambridge University Press, Adelaide, 1989)

13. T. Nakamura, S. Kaneko, Flow Induced Vibrations (Elsevier Science, Tokyo, 2008)

14. Y.J. Kwon, Journal of Mechanical Science and Technology 22(11) pp. 2038-2047 ( Korean Society of Mechanical Engineers, South Korea, 2008)

15. D. N. Ghista, A. P. Rao, J. of Biomechanics, 5(3) pp. 295-296. (Elsevier BV, Netherland, 1972)

16. A. Cataloglu, R. E. Clark, P. L. Gould, Jr. of Biomechanics, 10(3) pp. 153-158 (Elsevier BV, Netherland, 1977).

17. Y. J. Kwon, JSME International Journal Series A, 46(4) pp.550-558. (Japan Society of Mechanical Engineers, Japan, 2003)

18. H. Reul, A. Vahlbruch, M. Giersiepen, V. Hirtz and S. Effert, Jr. Biomech. 23 pp. 181-191 (Elsevier BV, Netherland, 1990)

19. M.D. de Tullio, G. Pedrizzetti, and R. Verzicco, Acta Mech. 216 pp. 146-163 (Springer Verlag, Germany, 2010)

20. S. Annerel, T. Claessens, P. Van Ransbeeck, P. Segers, Vierendeels J, Aortic Valve pp. 29-39 (Intech, Croatia, 2011)

21. A.C. Guyton and J. Hall, Textbook of medical physiology (SAUNDERS ELSEVIER, Philadelphia,1994)

22. M.S. Nasif, S.K. Kadhim, H.H. Al-Kayiem, R Al Waked, ARPN Jr. of Engg. and App. Sci., 11 pp. 11971-1197 (Asian Research Publishing Network (ARPN), Pakistan, 2016) 